proportion of TST conversion during immunotherapy was found. According to the immunomodulatory therapy, no differences were found among latent TB patients, active TB disease and no infection with the use of conventional DMARD therapy, but a positive association between latent TB and the use of biologic therapy was recognized. Low prevalences of opportunistic infections (i.e., Hepatitis B and C, syphilis and HIV) were found in this cohort, dispite the frequent use of biologic therapy.

Conclusions: In a TB-endemic population, higher prevalences of latent and active TB were found in patients with SpAs, when compared to the general population. Complete infectious screening is mandatory in patients under consideration of biologic agents, and close follow-up must be done to recognize TST conversion. References:

[1] Pérez-Díaz CE, Uribe-Pardo E, Calixto OJ, Faccini-Martínez ÁA, RodriguezMorales AJ. Infections with biological therapy: strategies for risk minimization in tropical and developing countries. J Infect Dev Ctries. 2016;10(12)

Disclosure of Interest: None declared

DOI: 10.1136/annrheumdis-2017-eular.3752

\section{SAT0414 DIFFERENCES IN CLINICAL PRESENTATION BY GENDER IN COLOMBIAN PATIENTS WITH SPONDYLOARTHROPATHIES}

M.A. Alzate ${ }^{1}$, F. Vargas $^{2}$, F. Ramirez ${ }^{2}$, D. Hernandez-Parra ${ }^{1}$,

J.C. Salazar-Uribe ${ }^{3}$, P. Ortiz-Salazar ${ }^{1}$, R. Pineda ${ }^{1}$ on behalf of Artmedica IPS, Medellin, Colombia. ${ }^{1}$ Clinical information group; ${ }^{2}$ Rheumatology division, Artmedica IPS; ${ }^{3}$ School of Statistics, Faculty of Sciences, National University of Colombia, Medellin, Colombia

Background: Spondyloarthropathies (SpAs) are a group of auto-inflammatory diseases, with overlapping symptoms, that include ankylosing spondylitis (AS), psoriatic arthritis (PsA), undifferentiated spondyloarthritis (Und SpA), enteropathic arthritis, and reactive arthritis (1). Historically, SpAs have been viewed as diseases that predominantly affected men (2).

Objectives: To analyze the influence of gender on disease patterns and therapeutic approach in a large cohort of Colombian patients with SpAs.

Methods: A cross-sectional study was conducted in 621 patients with SpAs, in whom clinical and therapeutic characteristics were analyzed based on gender. Statistical association was examined by means of Chi-square tests, Mann-Whitney test, and logistic regression analyses.

Results: The male-to-female ratio was 1,1:1 in this cohort. Younger age at diagnosis was found in males. AS was the most frequent disease (54,7\%), followed by PsA $(35,7 \%)$, and undifferentiated SpA $(9,5 \%)$. The male gender was positively associated to the presence of AS (OR 2,29 95\%IC 1,31-4,04), radiographic sacroilitis (OR 3,46 95\%IC 1,82-6,56), HLAB27 positivity (OR $1,9595 \%$ IC 1,31-2,91), low back pain (OR 1,85 95\% IC 1,34-2,54) and axial involvement (OR 1,98 95\% IC 1,42-2,77). According to the therapeutic profile, female gender was positively associated to the use of conventional DMARD therapy (i.e., methotrexate $(p=0,03)$, leflunomide $(p=0,0057)$, chloroquine $(p=0,013)$ ), while male patients were more associated to the use of biologic therapy.

Table 1. General characteristics of patients with $\mathrm{SpAs}$ by gender

\begin{tabular}{|c|c|c|c|c|c|c|c|}
\hline & \multicolumn{2}{|c|}{ All $(\mathrm{N}=621)$} & \multicolumn{2}{|c|}{ Male $(\mathrm{N}=328)$} & \multicolumn{2}{|c|}{ Female $(\mathrm{N}=293)$} & $\mathrm{p}$-value \\
\hline Age (mean) & \multicolumn{2}{|c|}{49,4} & \multicolumn{2}{|c|}{48,6} & \multicolumn{2}{|c|}{50,2} & 0,15 \\
\hline Age at diagnosis (mean) & \multicolumn{2}{|c|}{38,9} & \multicolumn{2}{|c|}{37,2} & \multicolumn{2}{|c|}{40,6} & 0,0042 \\
\hline \multirow[t]{2}{*}{ Years of evolution (mean) } & \multicolumn{2}{|c|}{9,8} & \multicolumn{2}{|c|}{10,6} & \multicolumn{2}{|c|}{9,1} & 0,02 \\
\hline & $\mathrm{N}$ & $\%$ & $\mathrm{~N}$ & $\%$ & $\mathrm{~N}$ & $\%$ & \\
\hline Age at onset $<45$ years & 469 & 75,5 & 257 & 78,3 & 212 & 72,3 & 0,008 \\
\hline \multicolumn{8}{|l|}{ Diagnosis } \\
\hline AS & 340 & 54,7 & 208 & 63,4 & 132 & 45,1 & \\
\hline PsA & 222 & 35,7 & 96 & 29,2 & 126 & 43 & $<0.0001$ \\
\hline Und SpA & 59 & 9,5 & 24 & 7,3 & 35 & 11,9 & \\
\hline Low back pain & 342 & 55,1 & 204 & 62,2 & 138 & 47,1 & 0,0002 \\
\hline Arthritis & 411 & 66,2 & 215 & 65,5 & 196 & 66,9 & 0,72 \\
\hline Enthesitis & 217 & 34,9 & 125 & 38,1 & 92 & 31,4 & 0,08 \\
\hline Dactylitis & 116 & 18,6 & 54 & 16,4 & 62 & 21,2 & 0,13 \\
\hline Uveitis & 92 & 14,8 & 52 & 15,8 & 40 & 13,6 & 0,44 \\
\hline Psoriasis & 225 & 36,2 & 98 & 29,8 & 127 & 43,3 & 0,0005 \\
\hline Sacroilitis (Rx) & $70 / 171$ & 40,9 & $46 / 82$ & 56,1 & $24 / 89$ & 26,9 & 0,0001 \\
\hline Sacroilitis (MRI) & $203 / 279$ & 72,7 & $102 / 136$ & 75 & $101 / 143$ & 70,6 & 0,41 \\
\hline HLA-B27 & $284 / 438$ & 64,8 & $176 / 246$ & 71,5 & 108/192 & 56,2 & 0,0009 \\
\hline Axial & 397 & 63,9 & 234 & 71,3 & 163 & 55,6 & $<0.0001$ \\
\hline Peripheral & 488 & 78,6 & 254 & 77,4 & 234 & 79,8 & 0,46 \\
\hline Both & 264 & 42,5 & 160 & 48,8 & 104 & 35,5 & 0,0008 \\
\hline
\end{tabular}

Conclusions: In this Colombian large sample with $\mathrm{SpA}$, male patients have a younger onset of disease, higher proportion of axial involvement, HLAB27 positivity, evidence of radiographic sacroilitis and higher use of anti-TNF therapy. References:

[1] Roussou E, Sultana S. Spondyloarthritis in women: differences in disease onset, clinical presentation, and Bath Ankylosing Spondylitis Disease Activity and Functional indices (BASDAI and BASFI) between men and women with spondyloarthritides. Clin Rheumatol. 2011;30(1):121-7.

[2] Ibn Yacoub Y, Amine B, Laatiris A, Hajjaj-Hassouni N. Gender and disease features in Moroccan patients with ankylosing spondylitis. Clin Rheumatol. 2012;31(2):293-7.

Disclosure of Interest: None declared
DOI: 10.1136/annrheumdis-2017-eular.3560

\section{SAT0415 HIGH PREVALANCE OF HIP ARTHRITIS IN PATIENTS WITH ANKYLOSING SPONDYLITIS TREATED WITH TNF INHIBITORS}

M. Konsta ${ }^{1,2}$, M.T. Nurmohamed ${ }^{2}$, A. lliopoulos $^{1}$, J.C. van Denderen ${ }^{2}$,

I. Visman ${ }^{2}$, P.P. Sfikakis ${ }^{1}$, I.E. van der Horst-Bruinsma ${ }^{2} .{ }^{1}$ First Department of Propaedeutic Internal Medicine, Rheumatology Department, Joined

Rheumatology Program, National and Kapodistrian University of Athens, Medical School, Athens, Greece; ${ }^{2}$ Amsterdam Rheumatology and Immunology Center, Amsterdam, Netherlands

Background: Hip involvement is the most frequent extraspinal arthritic manifestation of Ankylosing Spondylitis (AS) and a common cause of disability. It is present in $24 \%$ to $36 \%$ of AS patients, leading to total hip replacement (THR) in $5 \%$.

Objectives: To examine the prevalence of hip arthritis in patients with AS under TNF-inhibitor (TNFi) treatment, to identify predictors of its development and possible gender differences.

Methods: Consecutive TNFi-naïve AS patients (fulfilling the modified New York criteria) who were eligible for TNFi treatment were included. At baseline (before the start of TNFi), disease activity and function were recorded by BASDAI, ASDAS-CRP/ESR, BASFI and BASMI. Anteroposterior x-rays of the pelvis and lateral $\mathrm{x}$-rays of cervical and lumbar spine were obtained at baseline and scored according to the BASRI-hip scoring system and mSASSS. Hip involvement was assessed both clinically (as pain, reduced range of motion and intermalleolar distance) and radiographically (BASRI-h score $\geq 2$ was defined as definitive hip involvement). Mann-Whitney, two-sample t-test and logistic regression analysis were applied. The groups' averages were expressed as mean $\pm S D$, or median (IQR) according to the normality of data.

Results: 298 consecutive AS patients (214 men, age: 49 \pm 12 years (mean $\pm S D$ ), disease duration: $23.8 \pm 11.8$ years) were included. Definite hip involvement was detected in 113/298 (38\%) patients. Bilateral THR and unilateral THR underwent $10 / 298(3.4 \%)$ and $9 / 298(3 \%)$ patients respectively. No gender difference in the prevalence of hip arthritis was observed (females: $26 / 84(31 \%)$ vs. males $87 / 214(40.8 \%)$. The patients with hip arthritis compared to those without had significantly higher disease activity scores (BASDAI (6.1 \pm 1.7 vs. $5.5 \pm 1.9$, $\mathrm{p}=0.008)$, ASDAS-CRP (3.9 \pm 0.8 vs. $3.4 \pm 0.9, \mathrm{p}=0.0001)$, CRP [16 (7.7-32) median (IQR) vs. 7 (2.9-22), $\mathrm{p}=0.0001]$, ESR [26 (10-42) vs. 15.5 (7-33), $\mathrm{p}=0.004$ ], higher BASFI-scores (6.3 \pm 2.1 vs. $4.8 \pm 2.3, p<0.0001)$, BASMI-scores (5.1 $\pm 2.3 v s$. $3.4 \pm 2, p<0.0001)$ and reduced intermalleolar distance $(89 \pm 23$ vs. $104.8 \pm 19 \mathrm{~cm}, \mathrm{p}<0.0001$ ). AS patients with hip arthritis also had significantly higher mSASSS-scores [15 (3-39) vs. $4(0-16), p<0.0001]$ more often syndesmophytes $[75 / 107(70.1 \%)$ vs.75/181 (41.4\%), $\mathrm{p}<0.0001]$ and peripheral arthritis [54/111 $(48.7 \%)$ vs. $68 / 184(37 \%), p=0.048)$. According to multivariate logistic regression analysis, independent risk factors for hip arthritis were: raised CRP (OR: $1.01 \mathrm{Cl}$ : 1.001-1.02), presence of syndesmophytes (OR: 2.6, Cl: 1.45-4.8) and a high BASFI (OR: 1.33, Cl: 1.1-1.5).

Conclusions: The prevalence of hip arthritis in AS is very high (1/3) and significantly related to high disease activity and a high mSASSscore. No gender difference in prevalence of hip arthritis was found. Considering the large impact on function, this manifestation might need more attention.

Disclosure of Interest: None declared

DOI: 10.1136/annrheumdis-2017-eular.6844

\section{SAT0416 ANKYLOSING SPONDYLITIS DISEASE ACTIVITY SCORE (ASDAS) IS ASSOCIATED WITH NSAID USE OVER TIME}

M.J. Carbo ${ }^{1}$, S. Arends ${ }^{1,2}$, F. Maas ${ }^{1}$, E. Bouwer ${ }^{1}$, R. Bos ${ }^{2}$, H. Bootsma ${ }^{1}$ E. van der Veer ${ }^{3}$, F. Wink ${ }^{2}$, A. Spoorenberg ${ }^{1,2}$. ${ }^{1}$ Rheumatology and Clinical Immunology, University Medical Center Groningen, Groningen; ${ }^{2}$ Rheumatology, Medical Center Leeuwarden, Leeuwarden; ${ }^{3}$ Laboratory Medicine, University Medical Center Groningen, Groningen, Netherlands

Background: Non-steroidal anti-inflammatory drugs (NSAIDs) are the cornerstone of conventional treatment in ankylosing spondylitis (AS). In case of insufficient response, tumor necrosis factor-alpha (TNF- $\alpha$ ) inhibitors are available. Still little is known about concomitant NSAID use.

Objectives: To investigate the longitudinal association between disease activity and NSAID use in established AS patients.

Methods: The present analysis is part of the GLAS cohort, an ongoing longitudinal observational axial spondyloarthritis (SpA) cohort study in daily clinical practice. During 52 weeks of follow-up, NSAID use was recorded prospectively. The ASAS-NSAID index was calculated using the dosage and frequency assessed retrospectively from clinical records. Disease activity was assessed using ASDAS, BASDAI, and serum CRP levels.

Generalized estimating equations (GEE) was used to evaluate NSAID use in relation to assessments of disease activity over time. NSAID use was analyzed using 4 parameters: NSAID use (yes/no), ASAS-NSAID index, low on demand use (index $\geq 10$ versus $<10$ ), and high use (index $\geq 90$ versus $<90$ ). Analyses were stratified for treatment regimen: patients starting TNF- $\alpha$ inhibitors and patients on conventional treatment.

Results: Of the 393 included AS patients, $67 \%$ were male, mean age was $44 \pm 13$ years, median symptom duration 15 years (IQR $8-24$ ), and $79 \%$ were 
HLA-B27 positive. In total, 254 (66\%) patients started TNF- $\alpha$ inhibitors and $139(34 \%)$ patients received conventional treatment. Patient characteristics were comparable between both groups, except higher disease activity, more often peripheral arthritis, and worse physical functioning in patients starting TNF$\alpha$ inhibitors. NSAID use and disease activity reduced significantly after starting TNF- $\alpha$ inhibitors and remained low and stable during follow-up. In the conventional treatment group, disease activity was low and NSAID remained stable at all visits. GEE analysis over time showed that NSAID use was significantly associated with disease activity (Table 1). In the TNF- $\alpha$ inhibitor group, a significant association of all NSAID parameters with ASDAS was found: NSAID use yes vs. no, ASAS-NSAID index, index $\geq 10$ vs. $<10$, and index $\geq 90$ vs. $<90$. Comparable results were found for BASDAI and CRP. The association between NSAID use and ASDAS remained significant in the 217 patients who used TNF- $\alpha$ inhibitors more than $80 \%$ of the follow-up time and when analyzing only 12 to 52 weeks of follow-up to exclude the initial effect of TNF- $\alpha$ inhibitors, although the regression coefficients were lower in these last analyses. In the conventional treatment group, a significant but less prominent association of NSAID parameters with ASDAS was found: NSAID use yes vs. no, index $>10$ vs. $<10$, and index $>90$ vs. $<90$. BASDAI was only significantly associated with on demand NSAID use. For CRP, no significant associations with NSAID use were found.

\begin{tabular}{|c|c|c|c|c|c|}
\hline & & $\mathrm{B}(95 \% \mathrm{Cl})$ & P-value & Interval & $\mathbf{n}$ \\
\hline \multicolumn{6}{|l|}{ TNF. a Inhibitors } \\
\hline NSAID use Yes & Complete group & $0.825(0.664 \cdot 0.985)$ & $<0.001$ & 1074 & 251 \\
\hline \multirow[t]{3}{*}{ ASAS-NSAID index } & Complete group & $0.009(0.007-0.012)$ & $<0.001$ & 1073 & 251 \\
\hline & TNF- $a \geq 80 \% *$ & $0.011(0.009-0.013)$ & $<0.001$ & 953 & 214 \\
\hline & 12-52 weeks" & $0.005(0.003-0.007)$ & $<0.001$ & 633 & 246 \\
\hline ASAS-NSAID inde $x \geq 10$ & Complete group & $0.831(0.672-0.990)$ & $<0.001$ & 1073 & 251 \\
\hline ASAS-NSAID inde $x \geq 90$ & Complete group & $0.855(0.682-1.028)$ & $<0.001$ & 1073 & 251 \\
\hline \multicolumn{6}{|l|}{ Conventional treatment } \\
\hline NSAID use Yes & Complete group & $0.250(0.006-0.493)$ & 0.045 & 315 & 131 \\
\hline ASAS-NSAID index & Complete group & $0.002(0.000-0.005)$ & 0.059 & 314 & 131 \\
\hline ASAS-NSAID inde $x \geq 10$ & Complete group & $0.223(0.022-0.425)$ & 0.030 & 314 & 131 \\
\hline ASAS-NSAID inde $x \geq 90$ & Complete group & $0.269(0.038-0.501)$ & 0.023 & 314 & 131 \\
\hline
\end{tabular}

"Subgroup analysis of patients who used TNF-a inhibitors $280 \%$ of the follow up time. "Analysis for 12 to 52 weeks of follow-uF (excluding baseline and 6 weeks).

Conclusions: In this observational cohort of established AS patients, NSAID use over time was significantly associated with ASDAS, which was most pronounced for patients treated with TNF- $\alpha$ inhibitors.

Acknowledgements: The GLAS cohort was supported by an unrestricted grant from Pfizer. Pfizer had no role in the design, conduct, interpretation, or publication of this study.

Disclosure of Interest: None declared

DOI: 10.1136/annrheumdis-2017-eular.1971

\section{SAT0417 GRADUAL PROGRESSIVE CHANGE TO EQUAL PREVALENCE OF ANKYLOSING SPONDYLITIS AMONG MALES AND FEMALES IN SWITZERLAND: DATA FROM THE SWISS ANKYLOSING SPONDYLITIS SOCIETY (SVMB)}

H. Baumberger ${ }^{1}, \underline{\text { M.A. Khan }}{ }^{2} .{ }^{1}$ PhD. First president of, Schweizerische Vereinigung Morbus Bechterew, Zurich, Switzerland; ${ }^{2}$ Professor Emeritus of Medicine, Case Western Reserve University, Cleveland $\mathrm{OH}$, United States

Background: Classic ankylosing spondylitis (AS) with radiographic sacroiliitis has long been considered to be more common in men than women. But this difference has gradually decreased with increasing recognition of this condition in women so that the more recent data suggest a range of $2: 1$ to $1.2: 1$ ratio in favor of men [1].
Objectives: To document greater disease recognition in women during the last 30 years in Switzerland as reflected by AS patient membership in the Swiss Ankylosing Spondylitis Society (SVMB) since its foundation in 1978 [2].

Methods: We reviewed the Society's quarterly newsletters that have kept record since 1980 not only of the number of members, but also the percentage of males and females AS patients. We calculated yearly AS patient membership and also change in the male/female patient ratio (M:F).

Results: There has been a progressive decline in the M:F ratios since 1980 as shown in the Figure. There were 44 female forming $28 \%$ of the patient population, with a M:F ratio of 2.57 in 1980 . At the end of 2016, there are 1731 females forming $49 \%$ of the total number of patients, and the M:F ratio is now 1.03

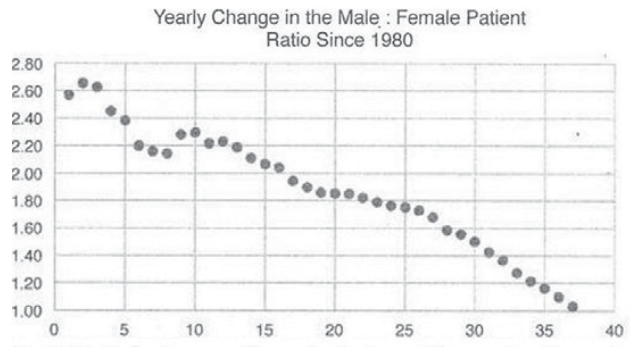

The M:F ratio is shown on the vertical axis, and the number of years is shown on the horizontal axis.

Conclusions: AS is now being recognized as often in females as in males, as reflected in the membership of SVMB over the last 36 years. There can be various reasons for this observation, one of them being the availability of better imaging tools to recognize AS/axial spondyloarthritis (axSpA), especially among women whose disease is clinically and radiologically less pronounced and is therefore often overlooked [2]. For example, the use of MRI (for early detection of spinal inflammation) and the ASAS criteria have resulted in $>50 \%$ females in a German cohort of patients with nonradiographic axSpA [3]. SVMB has played a major role in achieving greater disease recognition in Switzerland by increasing disease awareness and educating patients and their families, the general public, the governing bodies and the allied health professionals about AS, and by interacting closely with rheumatologists. Other possible factors influencing our data include: women outliving men, forming a little greater percentage of the general population, and possibly more likely to join patient self-help groups and societies, We did not investigate any gender difference in disease severity and clinical presentation. In conclusion, AS/axSpA almost equally afflicts men and women in Switzerland.

\section{References:}

[1] Khan MA. Accomplishments of Heinz Baumberger PhD: a remarkable patients with ankylosing spondylitis for 72 years. Clin Rheumatol. 2016;35(6):1637-41.

[2] Khan M.A. Ankylosing Spondylitis - Axial Spondylitis. Professional Communications Inc. 2016. pp. 1-333.

[3] Rudwaleit M, et al. The early disease stage in axial spondylarthritis: results from the German Spondyloarthritis Inception Cohort. Arthritis Rheum. 2009;60:71727.

Disclosure of Interest: None declared

DOI: 10.1136/annrheumdis-2017-eular.3961

\section{SAT0418 ANXIETY AND DEPRESSION ON DISEASE ACTIVITY AND QUALITY OF LIFE OF SPONDYLOARTHRITIS PATIENTS UNDER BIOLOGIC THERAPIES}

N. Madeira ${ }^{1}$, J. Borges $^{1}$, A. Cardoso ${ }^{2}$, L. Miranda ${ }^{1}$, F. Barcelos ${ }^{1}$, C. Miguel $^{1}$, C. Silva ${ }^{1}$, S. Fernandes ${ }^{1}$, R. Trinca ${ }^{3}$, D. Medeiros ${ }^{1}$, R. Campanilho-Marques ${ }^{1}$, H. Santos ${ }^{1}$, R. Leitão ${ }^{1}$, A. Faustino ${ }^{1}$. ${ }^{1}$ Rheumatology; ${ }^{2}$ Nutrition; ${ }^{3}$ Nursering, Instituto Português de Reumatologia, Lisbon, Portugal

Background: Several studies describe an association between anxiety, depression and disease activity in Spondyloarthritis ( $\mathrm{SpA})$.

Abstract SAT0418 - Table 1. Comparison of anxious vs non-anxious and depressive vs non-depressive patients

\begin{tabular}{|c|c|c|c|c|c|c|}
\hline & HADS-A $<8$ & HADS-A $\geq 8$ & $p$-value & HADS-D $<8$ & HADS-D $\geq 8$ & $p$-value \\
\hline Current age, mean $\pm S D$ (years) & $48.9 \pm 11.9$ & $52.6 \pm 10.8$ & 0.045 & $49.2 \pm 11.4$ & $53.2 \pm 11.5$ & 0.072 \\
\hline Age at diagnosis, mean $\pm S D$ (years) & $34.3 \pm 11.9$ & $40.2 \pm 11.5$ & 0.004 & $34.9 \pm 11.5$ & $40.9 \pm 12.5$ & 0.015 \\
\hline Age at 1 st bDMARD, mean $\pm S D$ (years) & $44.0 \pm 11.9$ & $48.7 \pm 10.64$ & 0.013 & $44.7 \pm 11.5$ & $48.7 \pm 11.6$ & 0.059 \\
\hline HADS-A, mean $\pm S D$ & $3.2 \pm 2.1$ & $10.2 \pm 2.1$ & - & $4.5 \pm 3.4$ & $9.7 \pm 3.1$ & $<0.001$ \\
\hline HADS-D, mean $\pm S D$ & $2.9 \pm 3.3$ & $8.3 \pm 2.7$ & $<0.001$ & $2.98 \pm 2.5$ & $10.3 \pm 2.3$ & - \\
\hline ASQoL, mean $\pm S D$ & $3.12 \pm 3.8$ & $10.6 \pm 4.5$ & $<0.001$ & $4.6 \pm 4.7$ & $9.63 \pm 5.8$ & $<0.001$ \\
\hline BASMI, mean $\pm S D$ & $3.1 \pm 1.8$ & $3.9 \pm 1.6$ & 0.003 & $3.2 \pm 1.7$ & $3.9 \pm 1.6$ & 0.016 \\
\hline BASFI, mean $\pm S D$ & $1.7 \pm 1.6$ & $4.1 \pm 2.3$ & $<0.001$ & $2.0 \pm 1.7$ & $4.3 \pm 2.6$ & $<0.001$ \\
\hline BASDAI, mean $\pm S D$ & $1.98 \pm 1.6$ & $4.5 \pm 2.1$ & $<0.001$ & $2.4 \pm 1.9$ & $4.5 \pm 2.3$ & $<0.001$ \\
\hline ASDAS, mean $\pm S D$ & $2.3 \pm 1.3$ & $2.6 \pm 1.1$ & 0.002 & $2.3 \pm 1.2$ & $2.7 \pm 1.2$ & 0.006 \\
\hline Patient's pain assessment (VAS), mean $\pm S D$ & $23.96 \pm 21.8$ & $41.2 \pm 22.1$ & 0.020 & $29.1 \pm 23.3$ & $38.2 \pm 23.0$ & 0.226 \\
\hline Patient's global assessment (VAS), mean \pm SD & $19.1 \pm 19.9$ & $42.8 \pm 23.1$ & $<0.001$ & $22.9 \pm 21.6$ & $42.6 \pm 24.5$ & $<0.001$ \\
\hline physician's global assessment (VAS), mean $\pm S D$ & $10.6 \pm 12.9$ & $20.1 \pm 16.8$ & $<0.001$ & $10.8 \pm 12.4$ & $23.95 \pm 17.8$ & $<0.001$ \\
\hline $\mathrm{TJC}$, mean $\pm \mathrm{SD}$ & $1.4 \pm 4.2$ & $4.3 \pm 9.99$ & 0.002 & $1.79 \pm 5.3$ & $4.45 \pm 10.3$ & 0.002 \\
\hline FACIT-F, mean $\pm S D$ & $42.4 \pm 7.8$ & $29.5 \pm 8.2$ & $<0.001$ & $40.4 \pm 8.6$ & $29.3 \pm 9.5$ & $<0.001$ \\
\hline EQ5D, mean $\pm S D$ & $0.51 \pm 0.11$ & $0.29 \pm 0.19$ & $<0.001$ & $0.48 \pm 0.13$ & $0.28 \pm 0.23$ & $<0.001$ \\
\hline
\end{tabular}

